\title{
Theoretical Study of Sand Entrainment and Deposits in Horizontal Oil Transport
}

\author{
Sanni Eshorame Samuel ${ }^{1, ~ *, ~ O l a w a l e ~ S u r a j u d e e n ~ A d e g b o y e g a ~}{ }^{2}$, Adefila Sunday Samuel ${ }^{1}$, \\ Emetere Moses ${ }^{3}$ \\ ${ }^{1}$ Department of Chemical Engineering, Covenant University, Ota, Nigeria \\ ${ }^{2}$ Department of Chemical Engineering, Ahmadu Bello University, Zaria, Nigeria \\ ${ }^{3}$ Department of Physics, Covenant University, Ota, Nigeria
}

Email address:

adexz3000@yahoo.com (S. E. Samuel)

\section{To cite this article:}

Sanni Eshorame Samuel, Olawale Surajudeen Adegboyega, Adefila Sunday Samuel, Emetere Moses. Theoretical Study of Sand Entrainment and Deposits in Horizontal Oil Transport. Science Research. Vol. 3, No. 6, 2015, pp. 314-323. doi: 10.11648/j.sr.20150306.18

\begin{abstract}
Sand deposition in horizontal pipes transporting crude oil and sand affects oil recovery and causes loss of pipe integrity. One way of avoiding sand deposition in lines is by identifying potential sand deposit points for mounting boosters to help boost the inertia force of the flowing stream. This paper investigates a model approach to the problem. Results from simulation give potential sand deposit points in a $12 \mathrm{~km}$ pipeline. The Reynolds numbers estimated, show significant variations between the 6 and $8 \mathrm{~km}$ points where viscous forces prevailed over inertia forces. Thus, the $6 \mathrm{~km}$ point is an ideal point for mounting a booster. Sand velocities remained constant at $0 \mathrm{~km}$ at different times down to the $8 \mathrm{~km}$ point although, the values differ axially per hour. Variations were incipient at the $10 \mathrm{~km}$ point through to the exit owing to hindered settling caused by inherent collisions of particles resting on the pipe wall. However, this also suggests that the $8 \mathrm{~km}$ point is a crucial point at or beyond which a booster pump is required to make up for the lost kinetic energy for a reliable and safe flow. Transport flow regimes were also investigated via parametric assessment on hourly basis.
\end{abstract}

Keywords: Sand Deposition, Horizontal Pipes, Boosters, Potential Deposit Points, Safe Flow

\section{Introduction}

Sand is usually produced when loosely packed formation zones are fractured. The oil and sand mix are transported thereafter to the heads of wells. At the head, horizontal transfer lines with or without screens, transport the residual sand in the oil to flow stations. Part of the transported sand could impinge or deposit on pipe wall due to pressure drop which may have resulted from flow constriction, high particle concentration, particle alignment within the flow and high viscosity among others. These phenomena usually lead to abrasion, corrosion, reduction in flow area and partial or total pipe blockage which gives rise to reduction in throughput from the lines. Sand exclusion methods, which involve the use of screens to remove some sand particles being transported with the crude, are continuously used to reduce sand concentration in the transported oil but cannot prevent deposition of the particles on the pipe wall. Also, the sand screens are quite laborious and expensive, Matthew et al ${ }^{[10]}$. This method of sand management requires intermittent maintenance of the screens to remove the trapped sand. In addition, the drop in pressure within the lines, gives rise to sand traps. The manpower loss associated with screen maintenance caused by particle-bed formation in the pipe constitutes economic loss. However, this paper examines a non-conventional method of sand management for the transport process which does not involve sand removal from the crude oil being transported. One such type of non-sand exclusion method ensures that pressure drop does not fall below a threshold either by augmentation of the motive force (e.g. with booster pumps) or by modification of the interactions among the constituents of the flowing system. Here, conditions which lead to sand entrainment were investigated. Oil recovery, the flow velocity and forces were obtained by numerical simulation with the aim of identifying the points where booster pumps would help improve the motive force along the pipeline. During this research, some experimental and theoretical works were revised which gave impetus to data generation: Andrew ${ }^{[1]}$ is a paper that looks into screenless methods of controlling sand. Sanni et $a l^{[13]}$ is a 
study on sand and crude oil transport in a horizontal pipe. The paper focused on sand deposition problems and the use of a non sand exclusion method as a means of controlling sand deposition in petroleum pipes against conventional methods. The method adopted, takes the form of mathematical equations. Fick's equation for diffusion was applied to modify the selected mathematical models and a third equation for sand deposit concentration was developed. Difference formulae were generated as a method of solution to the model by applying the Taylor's series expansion formula. The modified model gave good predictions of oil and sand volumes at the inlet and exit portions of the pipe as compared with results from experimental data. Smart ${ }^{[15]}$ gave a theoretical description on the evaluation of solid particle velocity in oil and gas pipelines. Particles movement such as those of $\mathrm{FeCO}_{3}, \mathrm{FeO}, \mathrm{FeS}, \mathrm{Fe}_{3} \mathrm{O}_{4}$, sand, weld spatter and salt which agglomerate to form a solid mass known as black powder in water, diesel, crude oil and natural gas were studied as they moved through horizontal pipes. The pipe sizes used were in the range of $219 \mathrm{~mm}$ ( 8 inches) to $1219 \mathrm{~mm} \mathrm{(48}$ inches). The actual flow velocities for the iron compounds in the fluids were found to be close because of their close densities (i.e. in the range of 3.8 to $4.82 \mathrm{~g} / \mathrm{cm}^{3}$ ). In addition, based on the findings, actual or critical velocity is an essential requirement for pigging process as it is useful in the control of deposit formation, scaling and pipe corrosion; thus, the velocity required to move black powder through natural gas was calculated as $2.8 \mathrm{~m} / \mathrm{s}$ for $219 \mathrm{~mm}$ and $4.2 \mathrm{~m} / \mathrm{s}$ for 1219 mm pipelines respectively. A paper by Smith and Waard ${ }^{[14]}$ focused on corrosion prediction and materials selection for oil and gas production environments using a model approach. The model was used to predict the corrosion rate of carbon steel, flow lines and tubing in the presence of $\mathrm{CO}_{2}$. The effects of dissolved corrosion products such as $\mathrm{FeCO}_{3}$, crude oil type / condensate, acetic acid, flow regime and other corrosion causatives (e.g. $\mathrm{H}_{2} \mathrm{~S}$ ) on corrosion rate of the pipes were evaluated. The roles of high temperature scaling and glycol injection for inhibition purposes were also studied and the findings give insight to ways of selecting corrosion resistant alloys via good life cycle cost analysis based on long and short term project requirements. The work of Matthew et al ${ }^{[11]}$ investigated the transport of field representative sand through a pipeline dip. Water, low viscosity black oil and two types of carboxy-methyl cellulose solutions having viscosities $150 \mathrm{cP}$ and $300 \mathrm{cP}$ were selected for the experiments to examine the influence of liquid viscosity on the transported sand. Stephen and Steven ${ }^{[16]}$ gave a study on the effects of fine grained sediment clay carrier fluid on the hydraulic gradient of sand-sized sediments in the range of 600-2000 microns in a $103 \mathrm{~mm}$ diameter pipeline. They determined sand concentration effect on hydraulic gradient. Fadel et al ${ }^{[7]}$ gave the description of an experimental technique for the accurate determination of the critical deposition velocity of particles associated with the transport of slurries in horizontal or slightly inclined pipes. In their work, visual observations were made of spherical and ellipsoidal pink garnet particles of 10 , 20 and 30 percent solids concentration with an average particle size and mean particle diameter of $100 \mu \mathrm{m}$ as they dragged along the bottom of a clear polycarbonate pipe test section of a slurry pipe loop. These works gave insight to critical parameters to be evaluated. To date, a model approach to sand corrosion control is yet to be established. Based on the works of Doan et al ${ }^{[3,4]}$, a new model was developed which aims at describing the laminar and turbulent flow behavior of sand and crude oil in a horizontal pipe between the head of a well and its flow station.

\section{Simulation of Sand Deposition}

The model for crude oil and sand transport in horizontal pipe as modified in Sanni et al ${ }^{[13]}$ is represented by Equations $1-5$.

$$
\begin{aligned}
& \frac{\partial \varphi}{\partial t}+\frac{\partial}{\partial z}\left(\varphi w_{s}\right)=0 \\
& \frac{\partial \sigma}{\partial t}+\frac{\partial}{\partial z}\left(\sigma w_{s}\right)=0 \\
& \frac{\partial \varepsilon}{\partial t}+\frac{\partial}{\partial z}\left(\varepsilon w_{f}\right)=0 \\
& \frac{\partial}{\partial t}\left(\Psi w_{s}\right)+\left(\frac{\partial}{\partial z}\left(\Psi w_{s} w_{s}\right)\right)= \\
& -(\Psi g)-\frac{\Psi}{\rho_{s}} \frac{\partial P_{s}}{\partial z}+\frac{\beta}{\rho_{s}}\left(w_{f}-w_{s}\right)-\frac{P_{k}}{\rho_{s}} \frac{\partial \Psi}{\partial z} \\
& D=\frac{1}{6} * d * u^{\prime}
\end{aligned}
$$

\subsection{Model Calibration}

The equation used to evaluate the molecular diffusivity of the mixture is given by Equation 6 .

$$
D=\frac{1}{6} * d * u
$$

where:

$d=$ diameter of particle

$D=$ molecular diffusivity (coefficient of diffusion)

$u^{\prime}=$ average velocity of $\operatorname{mix}\left(\frac{\varphi w_{s}+\varepsilon w_{f}}{2}\right), w_{s}$ and

$w_{f}=$ sand and fluid velocities.

Using the data given in Sanni et al ${ }^{[13]}$,

$d=0.05 \mathrm{~m}, w_{s}=27.04 \mathrm{~m} / \mathrm{s}$ and $w_{f}=30.04 \mathrm{~m} / \mathrm{s}$

$\therefore D=D_{e}=0.2378 \mathrm{~m}^{2} / \mathrm{s}$ (effective diffusivity)

Then, the effective diffusivity $\varepsilon_{T}$, is given as:

$\varepsilon_{T}=\varepsilon_{1}+\varepsilon_{2}+\varepsilon_{3}=0.000001395+0.000267893$

$+0.002450926=0.00272 \mathrm{~m}^{2} / \mathrm{s}$ 


$$
D_{T} \text { (total diffusivity) } \begin{aligned}
& D_{T}=D_{e}+\varepsilon_{T}= \\
& (2.08+0.00272) \mathrm{m}^{2} / \mathrm{s}=2.08272 \mathrm{~m}^{2} / \mathrm{s}
\end{aligned}
$$

The Eddy diffusivities for the laminar sub-layer, buffer and turbulent core regions were estimated with Eddy diffusivity equations as contained in Escobedo et al ${ }^{[6]}$ and Sanni et al ${ }^{[13]}$.

For $r^{+}=2.5$

$$
\varepsilon_{1}=\left(\frac{\left(r^{+}\right)}{11.15}\right)^{3} * v
$$

But

$$
v=\frac{\mu}{\rho_{f}}
$$

Where:

$v=$ kinematic viscosity, $\mu=0.0971 \mathrm{~kg} / m . s$ (fluid viscosity) and $\rho_{f}=784.43 \mathrm{~kg} / \mathrm{m}^{3}$ (fluid density).

Then $\varepsilon_{1}=0.000001395 \mathrm{~m}^{2} / \mathrm{s}$

For $r^{+}=17.5$

$$
\left.\varepsilon_{2}=\left(\frac{\left(r^{+}\right)}{11.4}\right)^{2}-0.1923\right) v
$$

Then $\varepsilon_{2}=0.000267893 \mathrm{~m}^{2} / \mathrm{s}$

For $r^{+}=49.5$

$$
\begin{gathered}
\varepsilon_{3}=\left(\frac{\left(0.4 r^{+}\right)}{1} * v\right. \\
\varepsilon_{3}=0.002450926 \mathrm{~m}^{2} / \mathrm{s}
\end{gathered}
$$

However, $\varepsilon_{T}=\varepsilon_{1}+\varepsilon_{2}+\varepsilon_{3}=0.00272 \mathrm{~m}^{2} / \mathrm{s}$

$$
D_{T}=D_{e}+\varepsilon_{T}=(2.08+0.00272) \mathrm{m}^{2} / \mathrm{s}=2.08272 \mathrm{~m}^{2} / \mathrm{s}
$$

Total diffusivity $\left(D_{T}\right)=$ sum of molecular and Eddy diffusivities.

Where:

$\varepsilon_{1,} \varepsilon_{2}, \varepsilon_{3}=$ Eddy diffusivities in the laminar, laminar sub-layer and turbulent core regions respectively.

$$
r^{+}=\text {Dimensionless radial distance }
$$

\subsection{Closure Problem Resolution}

Note:

As contained in Sanni et al., ${ }^{[13]}$, the model has a solution because it consists of eight equations with eight unknown variables $\left(\varphi, \sigma, \Psi, \varepsilon, w_{s}, w_{f} P_{s}, P_{f}\right)$; hence the degree of freedom is zero.

The three additional equations to Equations 1-5 are:

$$
\begin{aligned}
& \text { (i) } \sigma+\varphi=\Psi \\
& \text { (ii) } \Psi+\varepsilon=1 \\
& \text { (ii) } P_{s}=P_{i}-P
\end{aligned}
$$

\subsection{Finite Difference Formulae}

Iteration formulae were generated so as to have a solution pathway for the parabolic model as suggested in Mitchell et al., ${ }^{[12]}$. The resulting equations are algebraic transforms of the partial derivatives obtained using the difference formulae. Data used to simulate the model are contained in Table 1.

The mass conservation formulae for the solid and fluid finite differences estimate $\Psi$ and $\varepsilon$ while, $\Psi w_{s}$ and $\varepsilon w_{f}$ were evaluated to obtain the velocities at different sand and oil concentrations. $\frac{\partial \Psi}{\partial z}$ was generated from the finite difference mass conservation equation for solid phase. $\rho_{s}, \rho_{f}$ were supplied while, the pressure differential terms $\frac{\partial P_{s}}{\partial z}, \frac{\partial P_{f}}{\partial z}$ were evaluated using the single pressure model of Sthumiller ${ }^{[17]}$ given as:

$$
\begin{aligned}
& P_{i}=P+\frac{1}{2}\left(\rho_{f} R \frac{d u}{d t} \operatorname{Cos} \theta\right)+\frac{1}{8} \rho_{f} u^{2}\left(9 \operatorname{Cos}^{2} \theta-5\right) \\
& P_{i}-P=\frac{1}{2}\left(\rho_{f} R \frac{d u}{d t} \operatorname{Cos} \theta\right)+\frac{1}{8} \rho_{f} u^{2}\left(9 \operatorname{Cos}^{2} \theta-5\right) \\
& \frac{P_{i}-P}{z_{2}-z_{1}}=\frac{1}{2\left(z_{2}-z_{1}\right)}\left(\rho_{f} R \frac{d u}{d t} \operatorname{Cos} \theta\right)+\frac{1}{8} \rho_{f} u^{2}\left(9 \operatorname{Cos}^{2} \theta-5\right)
\end{aligned}
$$

At the surface of a spherical particle, $\operatorname{Cos} \theta=0$, pressure is normal hence, $\theta=90^{\circ}$. Therefore, $P_{i}-P$ is proportional to the square of the relative velocity between the two phases, leading to the valid assumption; $P_{s}=P_{f}$

But,

$$
\frac{d u}{d t}=\frac{d w}{d t}=\frac{w_{f}-w_{s}}{t_{2}-t_{1}}
$$

$R=$ particle radius, $w_{f}=$ fluid velocity, $w_{s}=$ solid velocity, $t=$ time and $\theta=$ surface angle. The other variables yet unresolved are the interaction coefficient $(\beta)$ and the kinematic pressure $\left(P_{k}\right)$. Givler and Mikataranian ${ }^{[8]}$ formula given by Equation 18 was used for kinematic pressure evaluation.

$$
P_{k}=\frac{1}{2} \rho_{s} * h\left(\varphi^{\prime}\right) *\left|w_{f}-w_{s}\right| *\left|w_{f}-w_{s}\right|
$$

Where:

$h\left(\varphi^{\prime}\right)$ is the intra-phase momentum transfer function.

For $\varphi^{\prime} \leq 20 \%$ volume fraction, $\varepsilon=20 \%$ volume fraction

$$
h\left(\varphi^{\prime}\right)=1.0+4\left(\varphi^{\prime}\right)+10\left(\varphi^{\prime}\right)^{2}+18.36\left(\varphi^{\prime}\right)^{3}+29.44\left(\varphi^{\prime}\right)^{4}
$$

Table 1. Variation of the function $h\left(\varphi^{\prime}\right)$ with $\varphi^{\prime}$.

\begin{tabular}{ll}
\hline $\boldsymbol{\varphi}$ & $\boldsymbol{h}\left(\boldsymbol{\varphi}^{\prime}\right)$ \\
\hline 0.00 & 1.00 \\
0.0884 & 1.44 \\
0.1563 & 1.91 \\
0.2128 & 2.39 \\
\hline
\end{tabular}


When solid concentration $>20 \%$, the data in Table 1 as given in Doan et al., ${ }^{[4]}$ should be used.

The interaction coefficient $(\beta)$ for an isolated spherical particle in fairly uniform translation through a fluid is given by Doan et al., ${ }^{[3]}$. For $\varphi^{\prime} \leq 0.20$ (dilute suspension), $\quad \varepsilon=20 \%$ volume fraction

$$
\beta=\frac{0.75 C_{D} \varphi^{\prime} \varepsilon}{2 a s} *\left(\frac{\rho_{f}\left|\varepsilon w_{f}-\varphi^{\prime} w_{s}\right|}{\left(\varphi^{\prime}\right)^{2.65}}\right)
$$

For $\varphi^{\prime}>0.20$ (dense suspension),

$$
\beta=\frac{150\left(\varphi^{\prime}\right)^{2} \mu_{f}}{\varepsilon\left(2 a s^{+}\right)^{2}}+\frac{1.75 \varphi^{\prime} \rho_{f}\left|\varepsilon w_{f}-\varphi^{\prime} w_{s}\right|}{2 a s}
$$

$a$ = radius of spherical particle, $s=$ stopping distance of particle, $s^{+}=$dimensionless stopping distance of particle.

$\beta=$ interaction coefficient. The stopping distances; dimensional $(s)$ and dimensionless $\left(s^{+}\right)$in Equations 20 and 21 were calculated using Equations 22 and 23 respectively.

$$
\begin{gathered}
s=\frac{0.05 \rho_{s} d^{2} v_{a v g} \sqrt{\frac{f}{2}}}{\mu}+\frac{d}{2} \\
s^{+}=\frac{S v_{a v g} \sqrt{\frac{f}{2}}}{\nu}
\end{gathered}
$$

$\rho_{s}=$ particle density, $d=$ particle diameter, $v_{\text {avg }}=$ average velocity of particle, $\mu=$ dynamic viscosity of oil, $\nu$

\begin{tabular}{|c|c|c|}
\hline Parameter & Field value & $\begin{array}{l}\text { Scaled } \\
\text { value }\end{array}$ \\
\hline Sand and oil nominal velocities, $\mathrm{cm} / \mathrm{s}$ & $(27.04 \& 30.04)$ & $\begin{array}{l}(27.04 \& \\
30.04)\end{array}$ \\
\hline Base sediment and water, $\%$ & 14.64 & 14.64 \\
\hline Tubing oil volume, $\mathrm{m}^{3} / d$ & 802.52 & 802.52 \\
\hline Tubing head pressure, bar & 245.7 & 245.7 \\
\hline Produced water flow rate, $m^{3} / d$ & 182.6 & 182.6 \\
\hline Sand diameter, microns $\mu \mathrm{m}$ & $150-200$ & 0.05 \\
\hline Mass flow rate of sand, $g / s$ & $5.44 \mathrm{E}-05$ & 544 \\
\hline Sand density, $\mathrm{kg} / \mathrm{m}^{3}$ & 1705.44 & 1705.44 \\
\hline Oil viscosity, $\mathrm{kg} / \mathrm{m} . \mathrm{s}$ & 0.0971 & 0.0971 \\
\hline Pipe diameter, $m$ & 5.44 inches $(0.12)$ & 0.06 \\
\hline
\end{tabular}
$=$ kinematic viscosity and $f=$ friction factor.

\subsection{Model Validation}

Table 2. Field data for model validation.

Table 3 shows the measured, calculated values and percent errors estimated at the inlet and exit sections of the pipe. The results were obtained from Sanni et al., ${ }^{[13]}$.

Table 3. Compared results of field data with model estimates.

\begin{tabular}{llll}
\hline Position & $\begin{array}{l}\text { Measured } \\
\text { value (field) }\end{array}$ & $\begin{array}{l}\text { Calculated } \\
\text { value (model's) }\end{array}$ & \% error \\
\hline $\begin{array}{l}\text { Inlet mass flow rate of } \\
\text { oil }\end{array}$ & $10.47 \mathrm{~kg} / \mathrm{s}$ & $9.144 \mathrm{~kg} / \mathrm{s}$ & $-14.86 \%$ \\
$\begin{array}{l}\text { Inlet volume flow rate } \\
\text { of oil }\end{array}$ & $0.0117 \mathrm{~m}^{3} / \mathrm{s}$ & $0.0137 \mathrm{~m}^{3} / \mathrm{s}$ & $-3.08 \%$ \\
$\begin{array}{l}\text { Outlet mass flow rate } \\
\text { of oil }\end{array}$ & $8.79 \mathrm{~kg} / \mathrm{s}$ & $9.061 \mathrm{~kg} / \mathrm{s}$ & $-14.6 \%$ \\
$\begin{array}{l}\text { Outlet volume flow rate } \\
\text { of oil }\end{array}$ & $0.0112 \mathrm{~m}^{3} / \mathrm{s}$ & $0.01155 \mathrm{~m}^{3} / \mathrm{s}$ & $-3.13 \%$ \\
\hline
\end{tabular}

\section{Results and Discussion}

Tables 4 and 5 show the variation of sand concentration with time along the axial distance for a period of four hours.

\subsection{Numerical Analysis}

(i) Sand and oil concentrations

Table 4. Variation of sand concentration with time and axial distance between $t=1 \mathrm{hr}$ and $t=4 \mathrm{hrs}$.

\begin{tabular}{lllllll}
\hline \multirow{2}{*}{ Time, hr } & \multicolumn{2}{l}{ Distance, $\mathbf{m}$} & & & \\
\cline { 2 - 7 } & $\mathbf{0}$ & $\mathbf{2 , 0 0 0}$ & $\mathbf{4 , 0 0 0}$ & $\mathbf{6 , 0 0 0}$ & $\mathbf{8 , 0 0 0}$ & $\mathbf{1 0 , 0 0 0}$ \\
\hline 1 & 0.06 & 0.055 & 0.05 & 0.045 & 0.04 & 0.03500 \\
2 & 0.06 & 0.055 & 0.05 & 0.045 & 0.04 & 0.03500 \\
3 & 0.06 & 0.055 & 0.05 & 0.045 & 0.04 & 0.029991 \\
4 & 0.06 & 0.055 & 0.05 & 0.045 & 0.04 & 0.03500 \\
\hline
\end{tabular}

Solid phase concentration dropped from 0.06 volume fraction at the inlet to 0.03 (i.e. $50 \%$ decrease in concentration) volume fraction at the exit in one hour. At 0, 2,000, 4,000, 6000 and 8,000 metres, the calculated solid concentrations at one hour interval were, $0.06,0.055,0.05,0.045$ and 0.04 (i.e. $8.3 \%$ change for every two successive points) respectively. This result is shown in Table 4 which gives the estimated concentration at $\mathrm{t}=1,2,3,4$ hours. At the 10,000 metre section, sand concentration at one hour interval was 0.035 volume fraction for seven hours. It changed to 0.035001 $(0.003 \%$ increase $)$ at the eighth and ninth hours and varied at further times; see Figure 1, which is a plot of sand concentration along the axial distance).

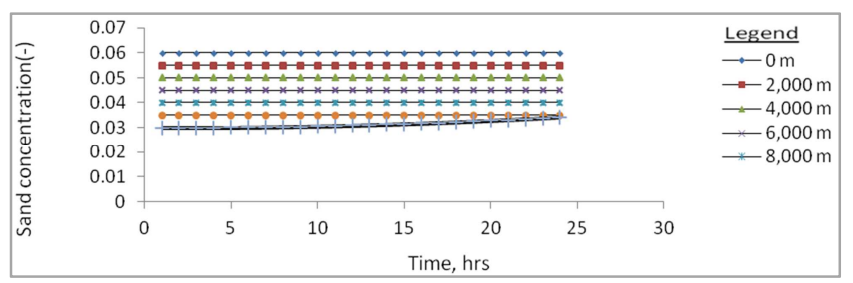

Figure 1. Concentration distribution of sand along axial distance. 
Furthermore, at the exit, were recorded variations in the estimated solid phase concentration (see Table 4). This is in line with Equations 1 and 2 which show that sand concentration is dependent on time and position.

For the oil, the concentration increased from 0.94 volume fraction at the inlet to 0.97 (i.e. about $3.19 \%$ change) volume fraction at the exit in one hour. At 0, 2,000, 4,000, 6000 metres, the calculated oil concentrations, at one hour interval were, $0.94,0.945,0.95,0.955$ (i.e. about $0.0053 \%$ change between two successive points) respectively. Table 5 gives the result of the calculated oil concentrations at $\mathrm{t}=1,2,3,4$ hours.

Table 5. Variation of oil concentration with time and axial distance between $t$ $=1 \mathrm{hr}$ and $t=4 \mathrm{hrs}$.

\begin{tabular}{llllllll}
\hline \multirow{2}{*}{$\begin{array}{l}\text { Time, } \\
\text { hr }\end{array}$} & \multicolumn{6}{l}{ Distance, $\mathbf{m}$} \\
\cline { 2 - 8 } & $\mathbf{0}$ & $\mathbf{2 , 0 0 0}$ & $\mathbf{4 , 0 0 0}$ & $\mathbf{6 0 0 0}$ & $\mathbf{8 0 0 0}$ & $\mathbf{1 0 , 0 0 0}$ & $\mathbf{1 2 , 0 0 0}$ \\
\hline 1 & 0.94 & 0.945 & 0.95 & 0.955 & 0.96 & 0.965 & 0.97 \\
2 & 0.94 & 0.945 & 0.95 & 0.955 & 0.96 & 0.965 & 0.96826 \\
3 & 0.94 & 0.945 & 0.95 & 0.955 & 0.96 & 0.964997 & 0.966525 \\
4 & 0.94 & 0.945 & 0.95 & 0.955 & 0.96 & 0.964991 & 0.964797 \\
\hline
\end{tabular}

At the 8,000 metre section, $0.96(0.0052 \%$ increase relative to the concentration at the previous point) was the calculated oil concentration when $\mathrm{t}=1 \mathrm{hr}$. This concentration remained unchanged up to the tenth hour. It changed slightly to 0.959999 (a decrease of $0.0001 \%$ ) at the eleventh hour and was the same for the next two hours. The results at the twelfth hour and above are shown in Figure 2.

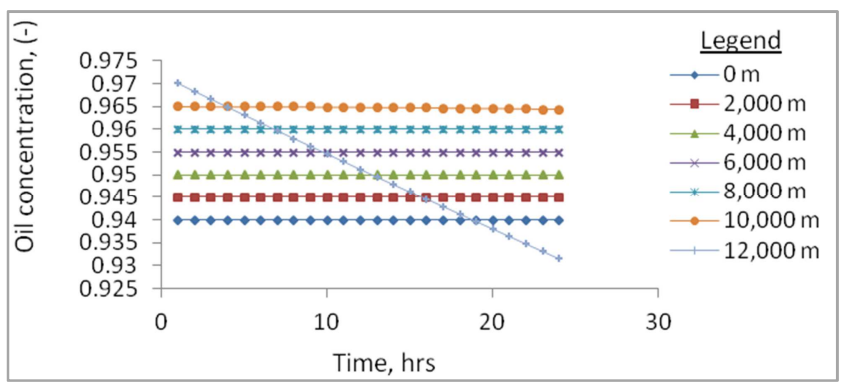

Figure 2. Concentration distribution of oil along axial distance.

(ii) Sand and oil velocities

Along the axial distance, the calculated sand velocities, at all times, were: $27.036 \mathrm{~m} / \mathrm{s}, 24.783 \mathrm{~m} / \mathrm{s}(8.3 \%$ change from the previous value), $22.53 \mathrm{~m} / \mathrm{s}$ (i.e. $9.1 \%$ decrease from the preceding value) and $20.277 \mathrm{~m} / \mathrm{s}(10 \%$ decrease from the preceding value) at $0,2,000,4,000$ and 6,000 metres respectively. At the 8,000 metre point, the calculated velocity was $24.032 \mathrm{~m} / \mathrm{s}(18.52 \%$ increase from the velocity at the previous point), for ten hours. It increased slightly at the eleventh hour and at further times. At the 10,000 metre point, the velocity was $15.771 \mathrm{~m} / \mathrm{s}$ (it decreased by $34.38 \%$ compared with the estimated value at the previous point) at $\mathrm{t}=$ 1 hour and $t=2$ hours. It reduced slightly in the next two hours but, increased at further times.

Table 6 shows calculated sand velocities at $\mathrm{t}=1,2,3,4$ hours. Equations 4 and 5 show that increased sand concentration gives rise to high sand velocities and vis-à-vis while Figure 3 shows the velocity profile for sand along the axial distance at the twelfth hour.

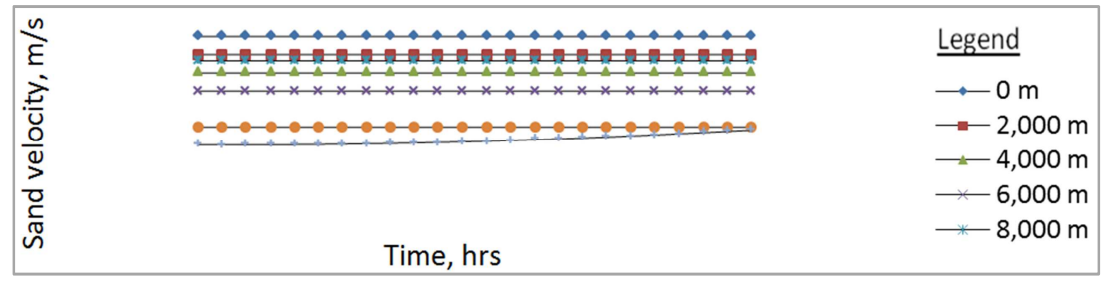

Figure 3. Sand velocity distribution with time along the axial distance.

Table 6. Variation of sand velocity with time and axial distance between $t=1 \mathrm{hr}$ and $\mathrm{t}=4 \mathrm{hrs}$.

\begin{tabular}{lllllll}
\hline \multirow{2}{*}{ Time, hr } & \multicolumn{2}{l}{ Distance, $\mathbf{m}$} & & & \\
\cline { 2 - 7 } & $\mathbf{0}$ & $\mathbf{2 , 0 0 0}$ & $\mathbf{4 , 0 0 0}$ & $\mathbf{6 , 0 0 0}$ & $\mathbf{8 , 0 0 0}$ & 15.771 \\
\hline 1 & 27.036 & 24.783 & 22.53 & 20.277 & 24.032 & 15.771 \\
2 & 27.036 & 24.783 & 22.53 & 20.277 & 24.032 & 13.518 \\
3 & 27.036 & 24.783 & 22.53 & 20.277 & 24.032 & 13.51398 \\
4 & 27.036 & 24.783 & 22.53 & 20.277 & 24.032 & 13.51801 \\
\hline
\end{tabular}

Table 7 shows oil velocity estimates at $t=1,2,3,4$ hours. At the exit, the calculated sand velocities varied at all times. The variation is due to changes in sand concentration since the total concentration of the mixture is a function of sand and oil concentrations.

Table 7. Variation of oil velocity with time and axial distance between $t=1 \mathrm{hr}$ and $\mathrm{t}=4 \mathrm{hrs}$.

\begin{tabular}{|c|c|c|c|c|c|c|c|}
\hline \multirow{2}{*}{ Time, hr } & \multicolumn{7}{|c|}{ Distance, $\mathbf{m}$} \\
\hline & $\mathbf{0}$ & 2,000 & 4,000 & 6,000 & 8,000 & 10,000 & 12,000 \\
\hline 1 & 28.2376 & 28.3878 & 28.538 & 28.6882 & 27.54067 & 26.57675 & 25.77945 \\
\hline 2 & 28.2376 & 28.3878 & 28.538 & 28.6882 & 28.8384 & 28.9886 & 29.08652 \\
\hline 3 & 28.2376 & 28.3878 & 28.538 & 28.6882 & 28.8384 & 28.98851 & 29.03442 \\
\hline 4 & 28.2376 & 28.3878 & 28.538 & 28.6882 & 28.8384 & 28.98832 & 28.98252 \\
\hline
\end{tabular}




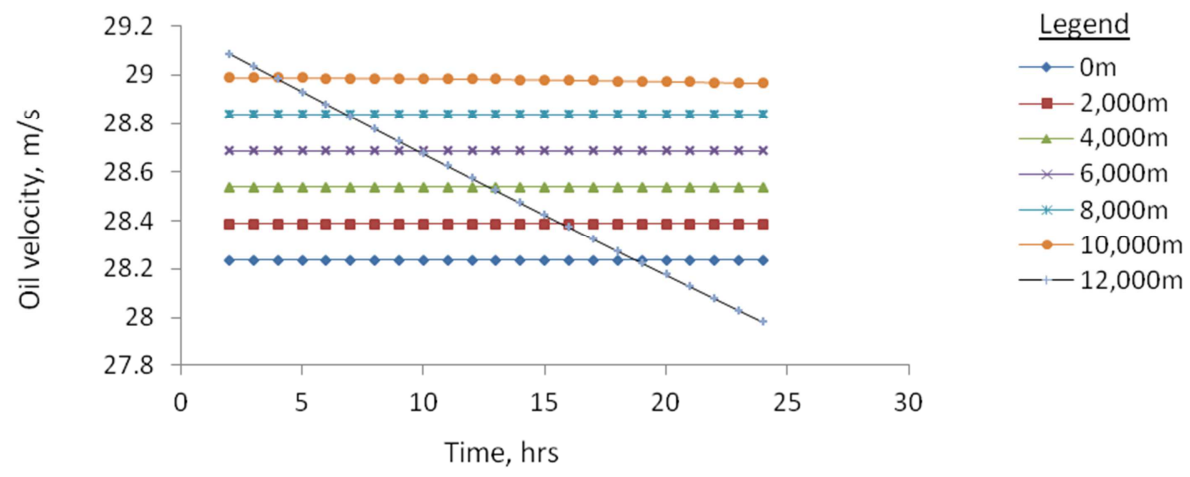

Figure 4. Oil velocity distribution with time along the axial distance.

For oil, the estimated velocities at, 0, 2,000, 4,000 and 6,000 metres were, $28.2376 \mathrm{~m} / \mathrm{s}, 28.3878 \mathrm{~m} / \mathrm{s}, 28.538 \mathrm{~m} / \mathrm{s}$ and $28.6882 \mathrm{~m} / \mathrm{s}$ (i.e. approximately $0.53 \%$ change for every two successive points) respectively, at all times. Figure 4 has the details of the results obtained at further times. At the 8,000 metre point, the calculated velocity was $27.54067 \mathrm{~m} / \mathrm{s}$ (about $4 \%$ decrease with reference to the value at the point just before it) at $\mathrm{t}=1$ hour and remained $28.8344 \mathrm{~m} / \mathrm{s}(4.7 \%$ increase) for the next six hours. At the eighth, ninth and tenth hours, the estimate was $28.83839 \mathrm{~m} / \mathrm{s}$ (about $0.014 \%$ increase) but, decreased at further times. At the last two points, the calculated velocities varied at all times; see Figure 4 for an outlook of oil velocity plot along the pipe axis. Equation 4 reveals that increased oil concentration gives rise to higher fluid velocities and vis-a-vis.

(iii) Reynolds number
Along the axial distance and at all times, the estimated Reynolds numbers for the first four positions were: 458.361 , $1456.083(217.67 \%$ increase over the value at the pipe inlet), 2426.805 (66.67\% increase over the preceding value) and 3397.527 (40\% increase with respect to the value at the 4,000 metre section) respectively. 8,000 metres away, the value reduced to 417.254 (87.72\% decrease compared with the value 6,000 metre away) in one hour and was not the same at other times. At the last two points, the calculated values were higher and varied at all times. It could be seen that points further away from the inlet experienced higher inertia than viscous forces; the 8,000 metre point is an exception where Reynolds numbers are seen to be the same after the first hour. Table 8 shows the results obtained at $\mathrm{t}=$ 1, 2, 3, 4 hours while Figure 5 can be viewed for results of $t$ $=5$ to $12 \mathrm{hrs}$.

Table 8. Variation of Reynolds number with time and axial distance between $t=1 \mathrm{hr}$ and $t=4 \mathrm{hrs}$.

\begin{tabular}{|c|c|c|c|c|c|c|c|}
\hline \multirow{2}{*}{ Time, hr } & \multicolumn{7}{|c|}{ Distance, $\mathbf{m}$} \\
\hline & $\mathbf{0}$ & 2,000 & 4,000 & 6,000 & 8,000 & 10,000 & 12,000 \\
\hline 1 & 485.361 & 1456.083 & 2426.805 & 3397.527 & 1417.254 & 4364.755 & 4952.753 \\
\hline 2 & 485.361 & 1456.083 & 2426.805 & 3397.527 & 1941.444 & 5338.971 & 6290.2 \\
\hline 3 & 485.361 & 1456.083 & 2426.805 & 3397.527 & 1941.444 & 5338.936 & 6267.527 \\
\hline 4 & 485.361 & 1456.083 & 2426.805 & 3397.527 & 1941.444 & 5338.861 & 6241.687 \\
\hline
\end{tabular}

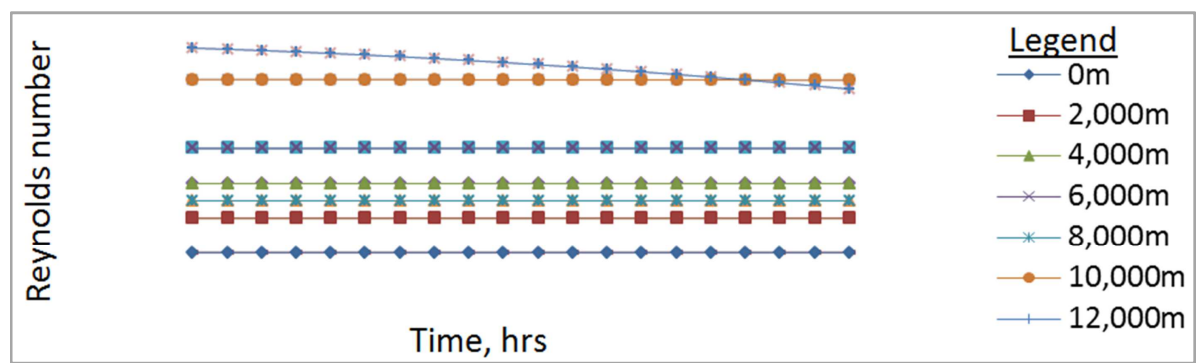

Figure 5. Reynolds number variation with time along the axial distance.

\subsection{Parametric Assessment of Sand Entrainment}

Practically, it is very difficult to predict sand production during a well's exploitation phase hence sand deposition may be difficult to predict using one technique or approach. All techniques-adopted to solve this problem had always been generic, Hongen et al., ${ }^{[9]}$. In the generic technique, many facts have already been known e.g. slip and settling velocity, Gibbs critical transport velocity for different sand sizes, theoretical modeling using the Stokes' law, Newtonian and non-Newtonian fluid flow principle, expansion schemes, Emetere, ${ }^{[5]}$; Bello et al., ${ }^{[2]}$. The generic technique could at most proffer solution to any or two kinds of solid - liquid transport flow regimes (saltation, intermediate, homogeneous and heterogeneous). Hence, it is important to think the following; when does a flow regime change? For what duration can a regime be sustained? How then can we restrain the flow regime to a 
particular kind? These questions may not be answered explicitly-generically. This then necessitates the need for the following parametric assessment of sand entrainment in accordance to strict adherence to energy conservation and
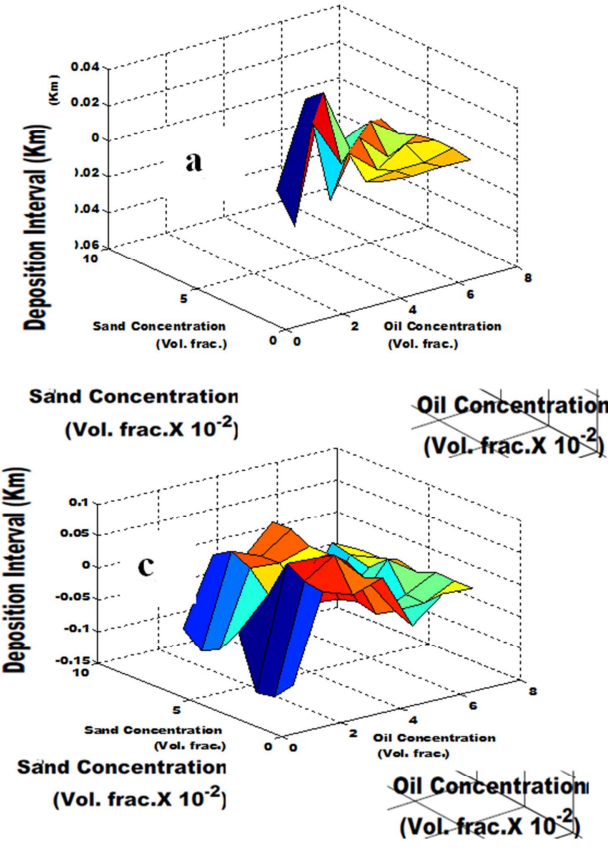

the inter-play of three major parameters i.e. sand sizes, mass, flow velocity (of solid - liquid) and viscosity of the fluids. The parametric assessment can be seen in Figures 6-8 below.
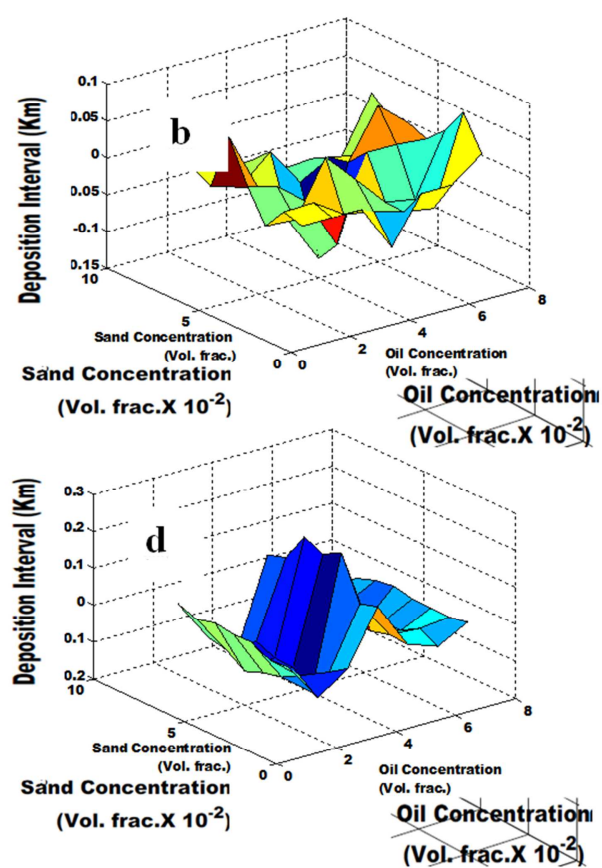

Figure 6. Parametric assessment when $P_{f}>P_{k}$. Fig 6a: low concentration when $\varepsilon<\Psi$; Fig $6 b$ : low concentration when $\varepsilon>\Psi$; Fig $6 c$ : medium concentration when $\varepsilon<\Psi ;$ Fig 6d: high concentration when $\varepsilon=\Psi$

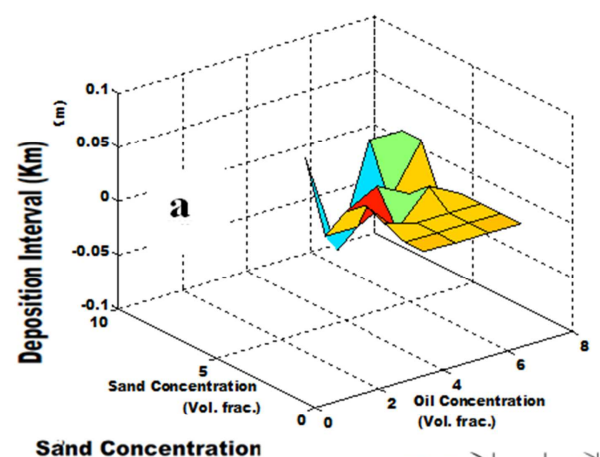

Sail Concentration

(Vol. frac.X $10^{-2}$ )

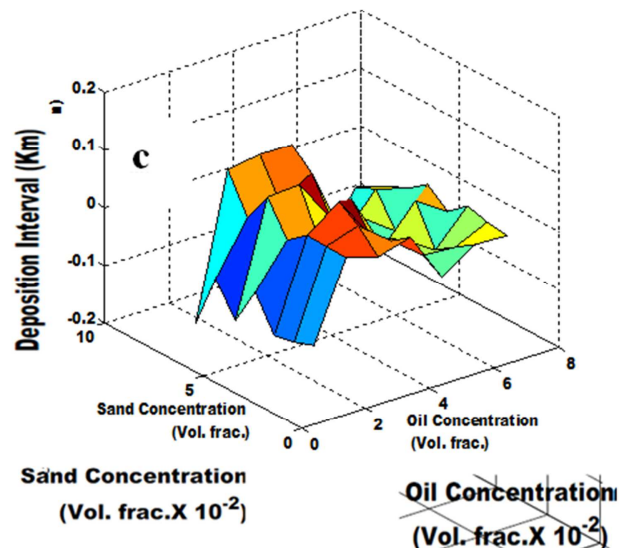

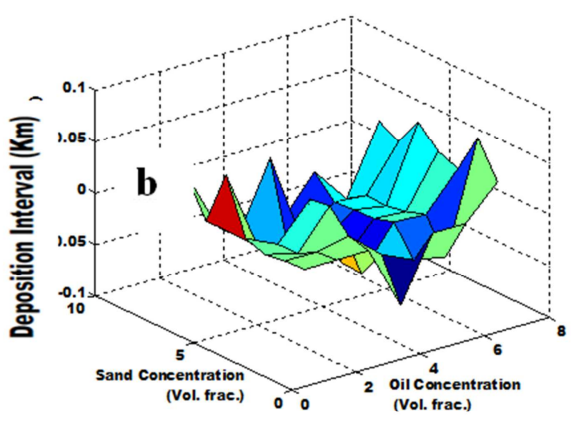

Sand Concentration (Vol. frac.X $10^{-2}$ ) (Vol. frac.X $10^{-2}$ )

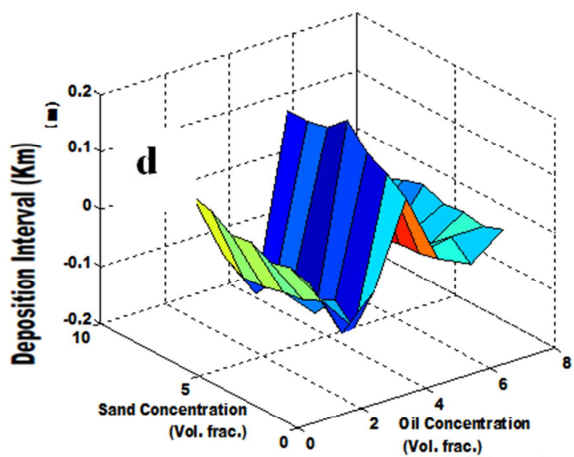

Sand Concentration (Vol. frac.X 10 ${ }^{-2}$ )

Qil Concentration (Vol.frac.x 10-2)

Figure 7. Parametric assessment when $P_{f}<P_{k}$. Fig $7 a$ : low concentration when $\varepsilon<\Psi$; Fig $7 b$ : low concentration when $\varepsilon>\Psi ;$ Fig $7 c$ : medium concentration when $\varepsilon<\Psi ;$ Fig 7 d: high concentration when $\varepsilon=\Psi$. 

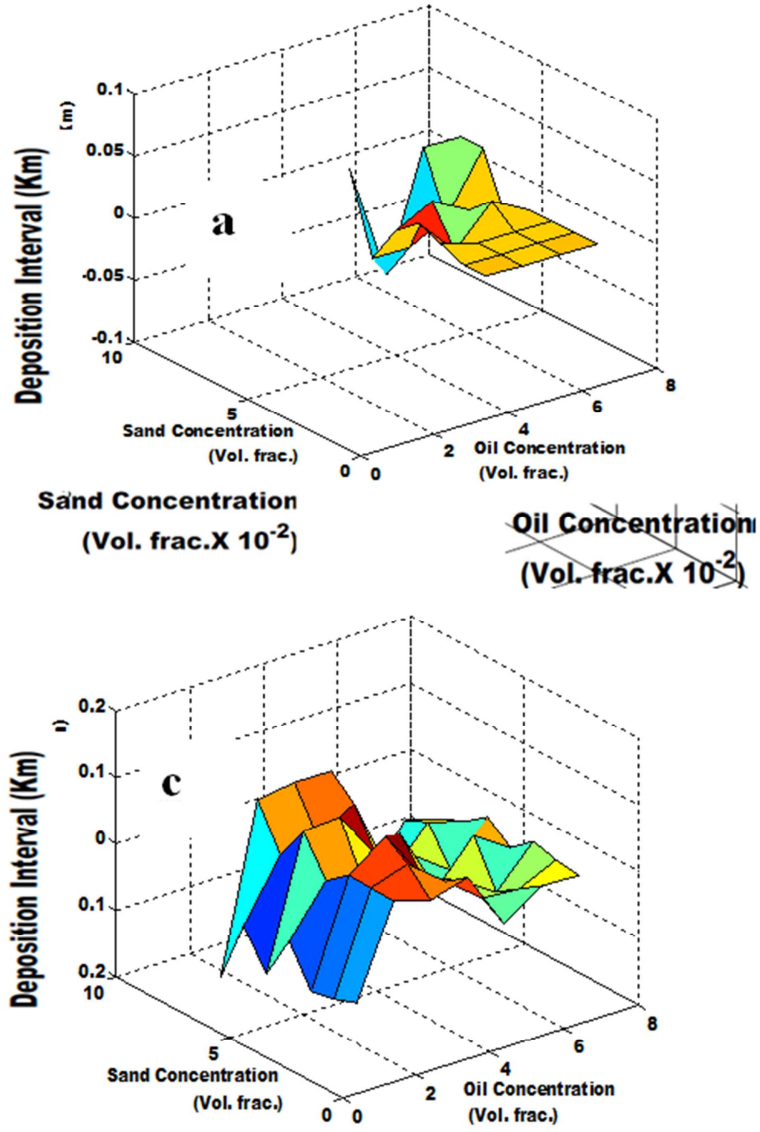

Sand Concentration

(Vol. frac.X 10-2)

\section{Oil Concentration}
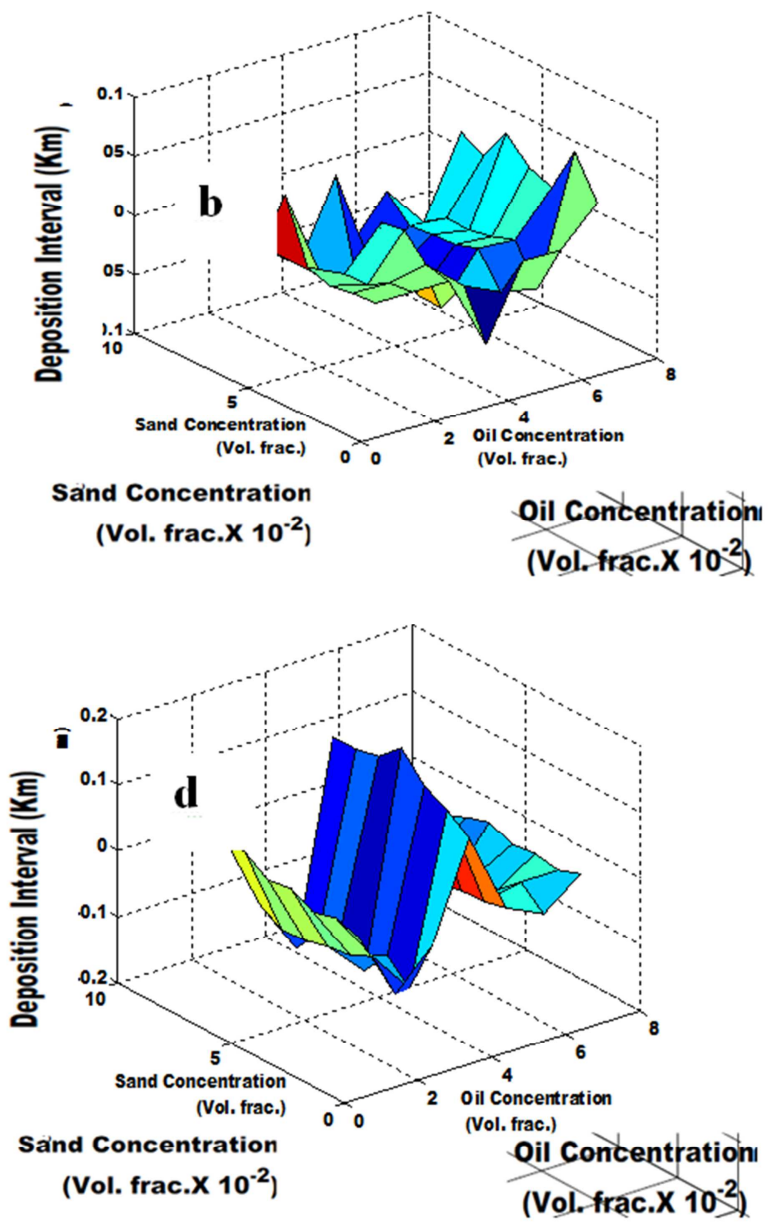

Figure 8. Parametric assessment when $P_{f}=P_{k}$. Fig $8 a$ : low concentration when $\varepsilon<\Psi ;$ Fig $8 b$ : low concentration when $\varepsilon>\Psi ;$ Fig $8 c$ : medium concentration when $\varepsilon<\Psi ;$ Fig $8 d$ : high concentration when $\varepsilon=\Psi$.

At low concentration, i.e. when $\mathrm{P}_{\mathrm{f}}>\mathrm{P}_{\mathrm{k}}$ and $\mathrm{e}<\mathrm{Y}$, the flow regime is intermediate i.e. the particulate sand is distributed within the homogeneous and heterogeneous flow regimes, see Figure 6a. Also, at low concentration when $\mathrm{P}_{\mathrm{f}}>\mathrm{P}_{\mathrm{k}}$ and $\mathrm{e}>\mathrm{Y}$, the flow regime is partially homogenous i.e. the sand particles are uniformly distributed along the cross section of the pipe, see Figure 6b; thus revealing more deposition intervals hence, the tendency of having segmental sand deposition is affirmed. At moderate concentration, when $\mathrm{P}_{\mathrm{f}}>\mathrm{P}_{\mathrm{k}}$ and $\mathrm{e}<\mathrm{Y}$, the flow regime is heterogenous i.e. the particulate sand shows rapid settling along the cross section of the pipeline as shown in Fig 6c. At high concentration when $\mathrm{P}_{\mathrm{f}}>\mathrm{P}_{\mathrm{k}}$ and $\mathrm{e}=\mathrm{Y}$, the flow regime is the saltation type i.e. fluid turbulence is not sufficient to keep fast settling particles in suspension, see Figure $6 \mathrm{~d}$.

Again, at low concentration, when $\mathrm{P}_{\mathrm{f}}<\mathrm{P}_{\mathrm{k}}$ and $\mathrm{e}<\mathrm{Y}$, the flow regime is partially intermediate i.e. the particulate sand is distributed within the homogeneous and heterogeneous flow regimes, see Figure 7a. At low concentration when $\mathrm{P}_{\mathrm{f}}<\mathrm{P}_{\mathrm{k}}$ and $\mathrm{e}>\mathrm{Y}$, the flow regime is partially homogenous i.e. the particulate sand is uniformly distributed along the cross section of the pipe as shown in Figure $7 b$; there are also more deposition intervals hence, the tendency of having segmental depositions. At moderate concentration, when $\mathrm{P}_{\mathrm{f}}<\mathrm{P}_{\mathrm{k}}$ and $\mathrm{e}<\mathrm{Y}$, the flow regime is homogenous i.e. the particulate sand is uniformly distributed along the cross section of the pipe, see Fig 7c. Like in Figure 7b, there may be tendencies of deposition at close distances. At high concentration when $\mathrm{P}_{\mathrm{f}}<\mathrm{P}_{\mathrm{k}}$ and $\mathrm{e}=\mathrm{Y}$, the flow regime is homogenous i.e. the particulate sand is uniformly distributed along the cross section of the pipe, see Figure 7d.

At low concentration when $\mathrm{P}_{\mathrm{f}}=\mathrm{P}_{\mathrm{k}}$ and $\mathrm{e}<\mathrm{Y}$, the flow regime is partially homogeneous i.e. the sand particles is uniformly distributed along the cross section of the pipe, see Figure $8 \mathrm{a}$. At low concentration when $\mathrm{P}_{\mathrm{f}}=\mathrm{P}_{\mathrm{k}}$ and $\mathrm{e}>\mathrm{Y}$, the flow regime is partially homogenous i.e. sand particles are uniformly distributed along the cross section of the pipe as shown in Figure 8b; again, there are more deposition intervals. Hence, the tendency of having segmental depositions is affirmed. At moderate concentration, when $\mathrm{P}_{\mathrm{f}}=\mathrm{P}_{\mathrm{k}}$ and $\mathrm{e}<\mathrm{Y}$, the flow regime is heterogenous i.e. the particulate sand encounters rapid settling along the cross section of the pipeline, see Figure 8c. At high concentration when $\mathrm{P}_{\mathrm{f}}=\mathrm{P}_{\mathrm{k}}$ and $\mathrm{e}=\mathrm{Y}$, the flow regime mimics saltation i.e. fluid turbulence is not sufficient to keep fast settling particles in suspension, see Figure $8 \mathrm{~d}$.

\section{Conclusion}

The model describes laminar and turbulent transport of sand 
and oil through horizontal pipes. The model solution is a success and unique. The simulated results suggest that the new model can serve as an alternative means to sand management. The numerical results show that inertia forces play a crucial role in the transport process since higher Reynolds numbers indicate higher inertia forces relative to viscous forces and vice versa. The parametric assessments of kinematic and fluid phase pressure forces show that at high particle concentration, flow stratification or dense phase flow sets in because the flowing oil and the external forces are not sufficient to keep the particles in suspension. However, the inertia forces need to be sufficiently high to keep the particles entrained in the oil all through the transport process. Also, saltation situations where the fluid phase force just equals the kinematic force should be avoided. The simulation results confirm the reliability of the model as a predictive tool for indentifying potential sand deposit points for mounting boosters for overcoming flow restrictions and oil recovery.

\section{Nomenclature}

\begin{tabular}{|c|c|c|}
\hline Symbol & Designation & Unit \\
\hline$A$ & Cross-sectional area & $m^{2}$ \\
\hline$g$ & Gravitational acceleration & $m s^{-2}$ \\
\hline$P_{f}$ & Fluid phase pressure & $\mathrm{kgm}^{-1} \mathrm{~s}^{-2}$ \\
\hline$P_{k}$ & Kinematic pressure & $\mathrm{kgm}^{-1} \mathrm{~s}^{-2}$ \\
\hline$P_{s}$ & Solid phase pressure & $\mathrm{kgm}^{-1} \mathrm{~s}^{-2}$ \\
\hline$q_{f}$ & Volume flow rate of oil & $m^{3} s^{-1}$ \\
\hline$q_{s}$ & Volume flow rate of sand & $m^{3} s^{-1}$ \\
\hline$t$ & Time & $h r s, s$ \\
\hline$V_{m}$ & Volume of mixture & $m^{3}$ \\
\hline$V$ & Volume & $m^{3}$ \\
\hline$w_{f}$ & Oil velocity & $m s^{-1}$ \\
\hline$w_{s}$ & Sand velocity & $m s^{-1}$ \\
\hline$z$ & Axial distance & \\
\hline$\beta$ & $\begin{array}{l}\text { Fluid-particle interaction } \\
\text { coefficient }\end{array}$ & $\mathrm{kgm}^{3} \mathrm{~s}$ \\
\hline$\Delta z$ & Change in length & $m$ \\
\hline$\varepsilon$ & $\begin{array}{l}\text { Oil concentration } \\
\text { (volume fraction) }\end{array}$ & - \\
\hline$\varphi$ & $\begin{array}{l}\text { Suspended } \\
\text { sand concentration } \\
\text { (volume fraction) }\end{array}$ & - \\
\hline$\rho_{f}$ & Oil density & $\mathrm{kgm}^{-3}$ \\
\hline$\rho_{s}$ & Sand density & $\mathrm{kgm}^{-3}$ \\
\hline$\sigma$ & $\begin{array}{l}\text { Sand } \\
\text { deposit concentration }\end{array}$ & - \\
\hline
\end{tabular}

\section{Acknowledgment}

AFTRAC oil services in Trans-Amadi, PortHarcourt
Nigeria is appreciated for providing knowledge on sand monitoring practices.

\section{References}

[1] Andrew, A., Nobert, H., Steve, H., Badar, M., Enzor, P., Claude, R., and Ricardo, J. (2003). Screenless Methods to Control Sand. Oilfield Review. 6: 37 - 53.

[2] Bello, K. O., Oyeneyin. M. B. and Oluyemi, G. F.(2011) Minimum Transport Velocity Models for Suspended Particles in Multiphase Flow Revisited." SPE ATCE. Denver, Colorado: SPE 147045, 10.

[3] Doan, Q., Farouq, A., George, A. and Oguztoreli, M. (1996). Simulation of Sand Transport in Horizontal Well. International Conference on Horizontal Well Technology. Calgary, Canada. November pp. 18-20.

[4] Doan, Q., Farouq, A., George, A. and Oguztoreli, M. (2000). Sand Deposition Inside a Horizontal Well- A Simulation Approach. SPE Journal, 39: 33-40.

[5] Emetere, M, E. (2014). Analytical Temperature Profiling For Pipe Walls and Fluids Using Mathematical Experimentation. Advancement in Engineering. 2014 (1), Article ID 490302, doi.org/10.1155/2014/490302.

[6] Escobedo, J. and Mansoori, G.A. (1995). Solid Particle Deposition During Turbulent Flow Production Operations. In: Richardson, T.X. (Ed), Production Operations pp. 439-446. Proceedings of a Symposium held at the Oklahoma City, Dakota, USA, April, Symposium Series No. 29488, SPE, Dakota.

[7] Fadel, E. F., Daniel, F. J., Michael, I. K and Walter, P. R. (2002). Measurement of Critical Deposition Velocity in Slurry Transport Through a Horizontal Pipe. Results from Research, Pacific Northwest Laboratory, Richland (mimeograph).

[8] Givler, R.C. and Mikataranian, R.R. (1987). Numerical Simulation of Fluid-Particle Flows: Geothermal Drilling Applications. Journal of Fluids Engineering, 109: 324-331.

[9] Hongen, D., Dandan, H. and Wenxin, C., (2005) Sand Production Prediction and the Selection of Completion Methods for Horizontal Wells in Intercampo Oil Field, Venezuela. SPE Asia Pacific Oil and Gas Conference and Exhibition Jakarta, Indonesia SPE 93821, 12.

[10] Matthew, H., Craig, J., Juliane, H., Joel, M., Don, E., Martin, K., Schetky, L. and Philip, S. (2003). Development and First Application of Bistable Expandable Sand Screen. SPE Annual Technical Conference. Colorado, USA. October pp. 1-14.

[11] Matthew, J. S., Fairhurst, P. C. and Hill, J. T. (2001). Solids Transport in Multiphase Flows-Application to High Viscosity Systems. In: Annual Report 1999-2001 p.1, Upstream Petroleum Technology Research, British Petroleum Exploration Sunbury, UK.

[12] Mitchell, A.R., Andrew, R. and Griffiths, D.F. (1980). Finite Difference Methods in Partial Differential Equations. John Wiley and Sons, Chichester, USA.

[13] Sanni, E, S., Olawale, A, S and Adefila, S, S. (2015). Mathematical Modeling of Sand and Crude Oil Flow in Horizontal Pipes During Crude Oil Transportation. Hindawii Journal of Engineering, pp.1-7. 
[14] Smith, L. and Waard, K. (2005). Corrosion Prediction and Materials Selection for Oil and Gas Producing Environments. NACE International, Houston Texas USA. pp 1 - 14.

[15] Smart, J. (2009). Calculating Velocity for Solid Particle Movement in Oil and Gas Pipelines. Pipeline and Gas Journal, pp. $1-5$.
[16] Stephen, H. and Steven, R. (2002). Hydraulic Transport of Fine and Coarse Sand Sediment Mixtures in Pipelines. Journal of Transport Engineering, 128: 1-8.

[17] Stuhmiller, J.H. (1977). The Influence of Interfacial Pressure Forces on the Character of Two Phase Flow Model Equations. International Journal of Multiphase Flows, 3: 551-560. 